\title{
ANALISIS SPASIAL UNTUK MENGIDENTIFIKASI TINGKAT PENGANGGURAN TERBUKA BERDASARKAN KABUPATEN/KOTA DI PULAU JAWA TAHUN 2017*
}

\author{
Eka Amalia ${ }^{1}$ and Liza Kurnia Sari2‡ \\ 1BPS Kabupaten Kolaka Utara, Indonesia, eka.amalia@bps.go.id \\ 2Politeknik Statistika STIS, Indonesia, lizakurnia@stis.ac.id \\ ${ }^{\ddagger}$ corresponding author
}

Indonesian Journal of Statistics and Its Applications (eISSN:2599-0802)

Vol 3 No 3 (2019), 202 - 215

Copyright () 2019 Eka Amalia and Liza Kurnia Sari. This is an open-access article distributed under the Creative Commons Attribution License, which permits unrestricted use, distribution, and reproduction in any medium, provided the original work is properly cited.

\begin{abstract}
Unemployment is one of the economic problems faced by many countries. In Indonesia, the total workforce has reached 128.06 million and 7.04 million people are unemployed. The indicator to measure unemployment is open unemployment rate (TPT). Java Island becomes the island with the highest TPT, which is 4.04 million people, equivalent to 63.08 percent. The regions that have high TPT rates tend to be in the western region of Java, while the eastern region of Java is moderate. This is an initial allegation of regional influence so spatial analysis needs to be carried out. On the other hand, not many studies have included territorial effects. This study aims to spatially identify the influence of human development index (IPM), labor force participation rate (TPAK), minimum wage and the dependency ratio on the number of TPT in Java in 2017 with the geographically weighted regression (GWR) method. The results of this study indicate that there are differences in the influence of IPM, TPAK, minimum wage and the dependency ratio on TPT in each area in Java. The most significant independent variables and have a positive relationship are minimum wage. This research also shows that GWR is suitable to be applied in modeling the number of TPT regencies /cities in Java Island in 2017. The results of this study can be used by the government in determining the right policy by looking at regional aspects in overcoming unemployment.
\end{abstract}

Keywords: geographically weighted regression, open unemployment rate, spatial.

* Received Feb 2019; Accepted Jul 2019; Published online on Oct 2019 


\section{Pendahuluan}

Pengangguran merupakan masalah perekonomian yang dihadapi oleh banyak negara, termasuk Indonesia. Hampir tidak ada negara yang terbebas dari masalah pengangguran. Hal tersebut salah satunya disebabkan oleh laju pertumbuhan penduduk yang tinggi sehingga jumlah angkatan kerja setiap tahunnya bertambah, sementara pertumbuhan jumlah lapangan kerja yang tersedia tidak sebanding. Sukirno (2010) menyebutkan faktor lain yang menyebabkan pengangguran di antaranya perusahaan menggunakan peralatan produksi modern sehingga mengurangi penggunaan tenaga kerja, ketidaksesuaian antara keterampilan pekerja dengan keterampilan yang dibutuhkan dalam dunia industri, serta pilihan seseorang untuk menganggur karena ingin mencari pekerjaan lain yang lebih baik. Pengangguran dapat menimbulkan beberapa efek buruk yang bersifat ekonomi, politik, dan sosial. Selain itu, pengangguran tidak menggalakkan pertumbuhan ekonomi. Efek buruk terhadap perekonomian yang dapat timbul dengan adanya pengangguran di antaranya adalah tidak maksimalnya tingkat kemakmuran yang mungkin dapat dicapai dan pendapatan pajak pemerintah berkurang. Hal tersebut menunjukkan bahwa pengangguran merupakan masalah yang harus segera diselesaikan karena jika tidak bijak dalam menanganinya akan menimbulkan masalah-masalah lain.

Penanganan yang tepat dan cepat sangat diperlukan mengingat bahwa seseorang membutuhkan pekerjaan agar mendapatkan upah untuk memenuhi kebutuhan hidup. Pengangguran sendiri memiliki arti penduduk yang tidak berkerja tetapi sedang mencari perkerjaan atau sedang mempersiapkan suatu usaha baru atau penduduk yang tidak mencari pekerjaan karena sudah diterima bekerja tetapi belum mulai bekerja. Indikator untuk melihat tingkat pengangguran yaitu dengan menggunakan Tingkat Pengangguran Terbuka (TPT).

Berdasarkan data Badan Pusat Statistik (BPS) pada tahun 2017 terdapat 128,06 juta angkatan kerja dimana 7,04 juta di antaranya merupakan pengangguran. Pulau Jawa memberikan kontribusi terbanyak dalam menyumbangkan angka pengangguran yaitu 4,04 juta penduduk atau setara dengan 63,08 persen penduduk menganggur berada di Pulau Jawa. Selain itu, tahun 2017 TPT Indonesia per provinsi cenderung mengalami peningkatan dibandingkan tahun 2016. Dari 34 provinsi di Indonesia, sebanyak 18 di antaranya mengalami peningkatan TPT. Tiga di antara delapan belas provinsi yang mengalami peningkatan TPT di Indonesia terdapat di Pulau Jawa yaitu DKI Jakarta, Jawa Tengah dan Banten. Tingkat pengangguran pada masing-masing provinsi di Pulau Jawa adalah Provinsi DKI Jakarta sebesar 7,14 persen, Jawa Barat 8,22 persen, Banten 9,28 persen, Jawa Tengah 4,57 persen, DI Yogyakarta 3,02 persen, dan Jawa Timur sebesar 4 persen. Angka yang besar mengingat jumlah penduduk pada masing-masing provinsi tersebut cukup besar.

Sudah banyak penelitian yang membahas mengenai pengangguran bahkan sampai level kabupaten, namun masih jarang yang memasukkan efek kewilayahan padahal masing-masing daerah memiliki karakteristik yang berbeda. Dalam upaya mengurangi tingkat pengangguran pemerintah perlu mengambil kebijakan dengan melihat lebih dalam kondisi masing masing daerah agar kebijakan yang diambil dapat lebih berguna dan bisa diterapkan. Jadi, kebijakan dalam menangani TPT ini tidak saja dilakukan secara global, melainkan juga secara lokal karena perbedaan karakteristik masing-masing daerah yang berbeda. Anwar (2005) dalam Mulyani 
(2017) menyatakan bahwa perbedaan yang dimaksud yaitu perbedaan karakteristik dari limpahan sumber daya alam, perbedaan kemampuan sumber daya manusia, dan perbedaan potensi lokasi. Oleh sebab itu, dalam penelitian ini, dilakukan analisis mengenai tingkat pengangguran berdasarkan wilayah sehingga kebijakan yang nantinya akan diambil dapat lebih efektif dan efisien.

Penelitian ini bertujuan untuk mendapatkan gambaran umum mengenai TPT di Pulau Jawa tahun 2017 dan menganalisis faktor-faktor yang memengaruhinya. Untuk mencapai tujuan tersebut, penelitian ini menggunakan analisis spasial yang dilakukan secara lebih spesifik berdasarkan wilayah administrasi kabupaten/kota di Pulau Jawa. Perbedaan mendasar antar analisis spasial dengan analisis non spasial seperti regresi linier atau regresi data panel adalah parameter yang dihasilkan tidak lagi bersifat global, melainkan bersifat lokal sehingga memungkinkan untuk mengetahui kabupaten/kota mana saja yang memiliki pola spasial yang sama untuk diterapkan kebijakan yang tepat sesuai wilayah.

\section{Metodologi}

\subsection{Bahan dan Data}

Data yang digunakan dalam penelitian ini adalah data sekunder berupa data crosssection pada tahun 2017 dari 119 kabupaten/kota di Pulau Jawa yang didapatkan dari beberapa sumber, yaitu:

1. Data Tingkat Pengangguran Terbuka diperoleh dari BPS melalui publikasi statistik keadaan angkatan kerja tahun 2017.

2. Data Indeks Pembangunan Manusia (IPM) diperoleh dari publikasi BPS.

3. Data Upah Minimum Kabupaten/Kota (UMK) diperoleh dari Kementerian Ketenagakerjaan.

4. Data Rasio Ketergantungan diperoleh dari BPS melalui publikasi statistik kesejahteraan rakyat tahun 2017.

5. Data Tingkat Partisipasi Angkatan Kerja (TPAK) diperoleh dari BPS melalui publikasi statistik keadaan angkatan kerja tahun 2017.

\subsection{Metode Analisis}

Gambaran umum dari variabel penelitian diberikan melalui peta tematik. Sementara pengaruh IPM, UMK, rasio ketergantungan dan TPAK terhadap TPT di setiap kabupaten/kota diketahui dengan menggunakan metode Geographically Weighted Regression (GWR).

\section{a. Pembentukan Model GWR}

Pada regresi linier berganda dengan metode estimasi Ordinary Least Square (OLS) diperlukan terpenuhinya asumsi-asumsi klasik agar diperoleh hasil estimasi yang tepat. Apabila ada asumsi yang terlanggar maka model hasil OLS harus dievaluasi, misalnya dengan memberikan penimbang. Salah satu model regresi yang menggunakan penimbang adalah Geographically Weighted Regression (GWR). Model GWR adalah model regresi yang dikembangkan khusus untuk memodelkan 
data dengan variabel respon yang bersifat kontinu dengan mempertimbangkan aspek spasial atau keruangan. Pendekatan yang dilakukan dalam GWR adalah pendekatan titik, artinya dalam model GWR membutuhkan suatu referensi keruangan berupa suatu titik yang dapat mewakili informasi spasial untuk masing-masing observasi, umumnya informasi keruangan yang digunakan dalam model GWR adalah koordinat lintang (latitude) dan bujur (longitude). Dalam model GWR, nilai setiap parameter ditaksir pada setiap titik pengamatan sehingga setiap titik pengamatan mempunyai nilai parameter yang berbeda-beda.

Model umum GWR adalah:

$$
Y_{i}=\beta_{0}\left(u_{i}, v_{i}\right)+\sum_{k=1}^{p} \beta_{k}\left(u_{i}, v_{i}\right) X_{k i}+\varepsilon_{i}
$$

Keterangan:

$Y_{i} \quad$ : nilai variabel respon pada titik pengamatan ke- $i$

$X_{k i} \quad$ : nilai variabel penjelas ke-k pada titik pengamatan ke- $i$

$\beta_{k}\left(u_{i}, v_{i}\right)$ : parameter/koefisien regresi untuk variabel ke-k pada titik pengamatan ke$i$ dengan koordinat $\left(u_{i}, v_{i}\right)$

$\varepsilon_{i} \quad$ : error pada titik pengamatan ke- $i$

Nilai parameter ke-k di titik pengamatan ke-i ditaksir dengan formula berikut:

$$
\beta\left(u_{i}, v_{i}\right)=\left[X^{T} W\left(u_{i}, v_{i}\right) X\right]^{-1} X^{T} W\left(u_{i}, v_{i}\right) Y
$$

dengan $W\left(u_{i}, v_{i}\right)$ adalah matriks penimbang.

Taksiran parameter tidak hanya bergantung pada nilai variabel penjelas, tetapi juga pada bandwidth yang digunakan dalam menghitung penimbang (fungsi kernel). Bandwidth adalah radius daerah penaksiran yang berpusat di titik pengamatan ke-i. Titik pengamatan yang berada dalam daerah tersebut memiliki pengaruh dalam penaksiran parameter di titik pengamatan ke- $i$. Ada dua fungsi kernel yang dapat digunakan yaitu adaptive gaussian dan adaptive bisquare. Fungsi kernel yang dipilih adalah yang menghasilkan bandwidth optimum dengan melihat nilai Akaike Information Criterion (AIC) dan Cross Validation (CV). Semakin kecil nilai AIC dan CV yang dihasilkan fungsi kernel berarti semakin baik penimbang yang dihasilkan (Fotheringham et al., 2003).

\section{b. Evaluasi Model GWR}

Evaluasi model GWR meliputi uji variasi parameter, uji parsial parameter, dan evaluasi hasil model terbentuk. Uji variasi parameter dilakukan untuk melihat apakah besar pengaruh variabel penjelas di setiap wilayah memiliki perbedaan atau tidak, dengan kata lain apakah data mengandung heterogenitas spasial. Uji dilakukan dengan membandingkan model GWR yang diperoleh (GWR asli) dengan model GWR lain yang dibentuk dengan menganggap koefisien variabel ke-k konstan dan koefisien variabel lain bervariasi (GWR pengganti). Perbandingan ini dilakukan dengan melihat nilai Difference Of Criterion yang merupakan perbedaan nilai AIC dari model GWR asli dan model GWR pengganti. Jika model GWR pengganti lebih fit maka Difference Of Criterion bernilai positif yang berarti tidak ada variasi dari nilai koefisien variabel ke-k di setiap wilayah. Sedangkan jika model GWR asli lebih baik daripada model GWR pengganti maka Difference Of Criterion bernilai negatif sehingga dapat dikatakan nilai koefisien variabel ke-k berlaku lokal (Nakaya, 2012). 
Uji parsial parameter digunakan untuk melihat koefisien dari variabel apa saja yang signifikan secara statistik. Sementara evaluasi hasil model GWR yang terbentuk dilakukan melalui (i) pengujian heterogenitas spasial dengan menggunakan peta tematik dari variabel residual dan (ii) pengujian autokorelasi spasial dengan menggunakan statistik Moran's I dan Moran's scatterplot.

\section{Hasil dan Pembahasan}

\subsection{Gambaran Umum Tingkat Pengangguran Terbuka dan Faktor-faktor yang Memengaruhinya}

Pengangguran merupakan masalah yang terjadi hampir di semua negara. Upaya menekan angka pengangguran perlu dilakukan agar dampak negatif yang ditimbulkan dari masalah tersebut dapat dihindari. Untuk melihat besar pengangguran di digunakan suatu pengukuran yaitu TPT. Angka TPT merupakan persentase jumlah pengangguran terhadap angkatan kerja. Semakin tinggi nilai TPT di suatu wilayah menunjukkan bahwa semakin banyak angkatan kerja yang tidak terserap pasar tenaga kerja pada wilayah tersebut. Rata-rata TPT kabupaten/kota di Pulau Jawa sebesar 5,40 persen. Wilayah dengan angka TPT tertinggi yaitu Kota Cilegon sebesar 12,11 persen dan wilayah dengan TPT terendah yaitu kabupaten Pacitan sebesar 0,85 persen. Secara umum, keragaman angka TPT antarwilayah di Pulau Jawa sebesar 2,47 persen. Pola persebaran TPT pada tahun 2017 di kabupaten/kota di Pulau Jawa disajikan pada Gambar 1.
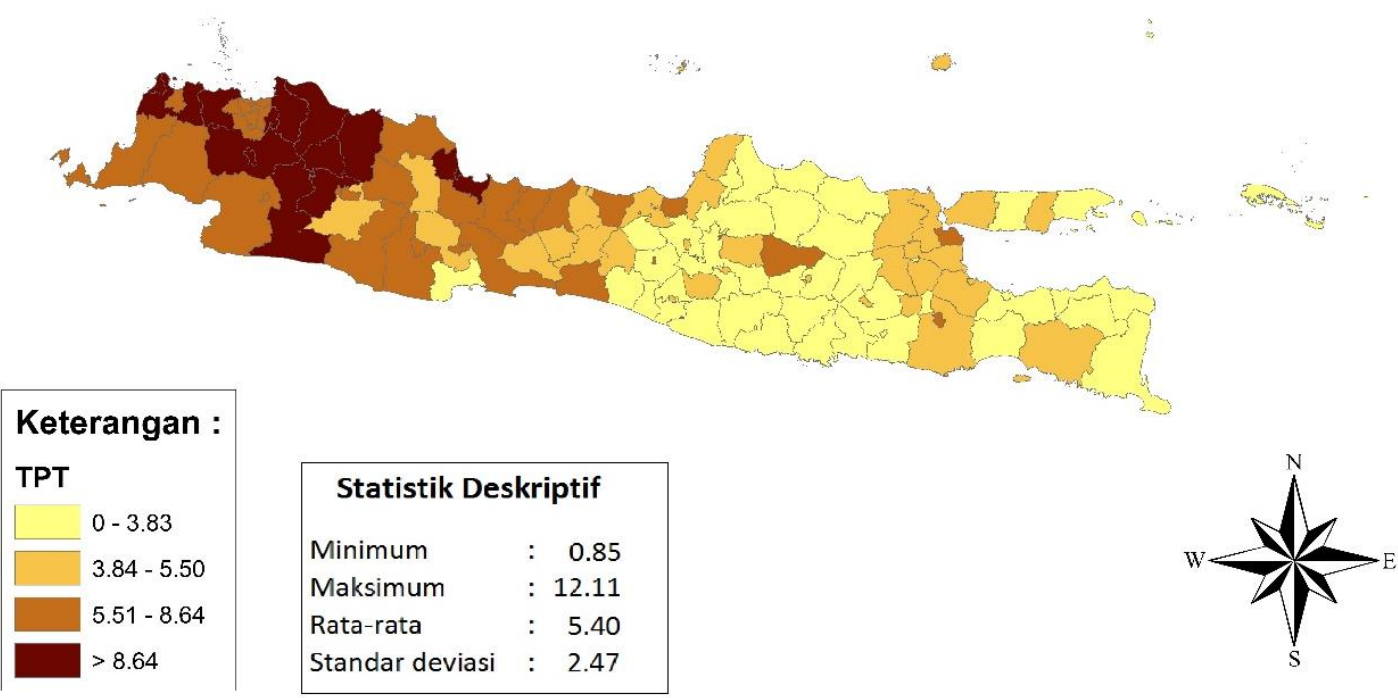

Keterangan: Peta tidak berskala

Gambar 1: Pola persebaran TPT menurut kabupaten/kota di Pulau Jawa tahun 2017.

Berdasarkan Gambar 1 dapat dilihat bahwa kabupaten/kota yang memiliki angka TPT jauh diatas rata-rata nasional sebesar 5,40 didominasi oleh wilayah bagian barat Pulau Jawa, yaitu kabupaten/kota yang berada di Provinsi Jawa Barat dan Banten diantaranya Bogor, Cianjur, Cirebon, Subang, Purwakarta, Karawang, Bekasi, Bandung Barat, Kota Bogor, Kota Cirebon, Kota Bekasi, Tangerang, Serang dan Kota 
Cilegon. Hal tersebut terjadi karena masih tingginya ketimpangan antara permintaan dan pasokan tenaga kerja. Ketidakselarasan terjadi mulai dari tingkat pendidikan hingga keterampilan kerja yang dibutuhkan oleh penyedia kerja. Selain itu banyaknya migran yang berasal dari kabupaten/kota di provinsi lain yang tidak terserap pasar tenaga kerja juga memberikan kontribusi terhadap angka TPT di wilayah tersebut. Sementara, wilayah bagian timur Pulau Jawa memiliki kecendrungan angka TPT lebih rendah. Hal tersebut terjadi karena banyak angkatan kerja yang terserap pada sektor pertanian. Selain itu, banyaknya penduduk yang merantau ke wilayah barat Pulau Jawa juga memberikan kontribusi terhadap penurunan angka TPT pada wilayah tersebut. Berdasarkan Gambar 1 juga dapat dilihat bahwa terdapat pengelompokan pada angka TPT di Pulau Jawa. Pola tersebut dapat dijadikan sebagai deteksi awal adanya autokorelasi spasial yang selanjutnya diteliti dengan statistik Moran's I.

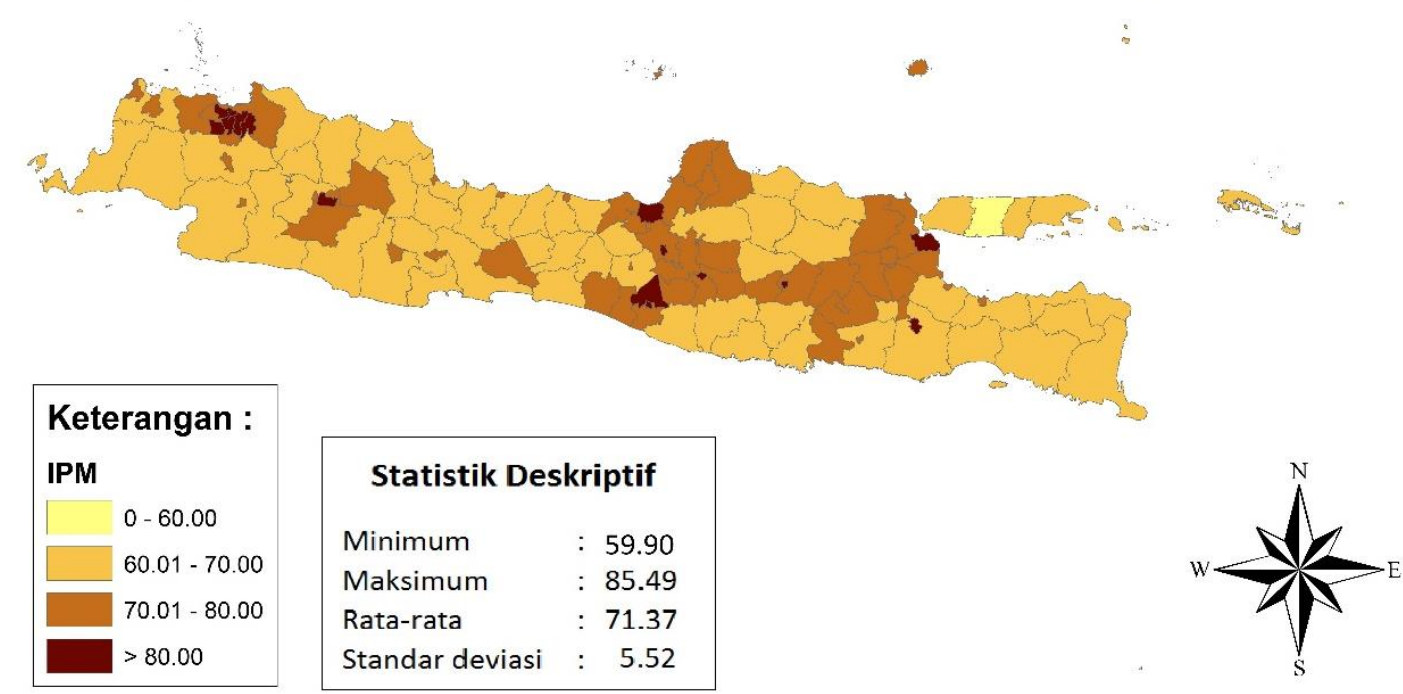

Keterangan: Peta tidak berskala

Gambar 2: Pola persebaran IPM menurut kabupaten/kota di Pulau Jawa tahun 2017.

Indeks Pembangunan Manusia merupakan ukuran yang penting untuk mengukur pencapaian hasil pembangunan dari suatu wilayah dalam tiga dimensi dasar pembangunan yaitu: lamanya hidup, pengetahuan dan standar hidup layak. Semakin tinggi nilai IPM suatu wilayah menunjukkan pembangunan manusianya semakin baik. Wilayah dengan IPM tertinggi yaitu Kota Yogyakarta sebesar 85,49 dan wilayah dengan IPM terendah yaitu Kabupaten Sampang sebesar 59,90 persen. Rata-rata IPM di Pulau Jawa sebesar 71,37 persen dengan tingkat keragaman IPM antarwilayah sebesar 5,52 persen. Berdasarkan Gambar 2 terlihat bahwa mayoritas IPM kabupaten/kota di Pulau Jawa memiliki IPM sedang yaitu dengan interval 60-70. Hal tersebut terjadi karena tingkat pendidikan penduduknya masih didominasi oleh lulusan sekolah menengah. Pola hidup sehat yang semakin berkurang juga berdampak terhadap angka IPM tersebut. Disisi lain, hanya beberapa kabupaten/kota di Pulau Jawa yang memiliki angka IPM sangat tinggi (diatas 80 persen) diantaranya Kota Jakarta Selatan, Kota Jakarta Timur, Kota Jakarta Pusat, Kota Jakarta Barat, Kota 
Bandung, Kota Bekasi, Kota Surakarta, Kota Salatiga, Kota Semarang, Sleman, Kota Yogyakarta, Kota Malang, Kota Madiun, Kota Surabaya dan Kota Tangerang Selatan. Kemudahan mengakses fasilitas kesehatan, pendidikan maupun fasilitas umum lainnya juga bisa jadi menjadi penyebab tingginya nilai IPM pada wilayah tersebut.

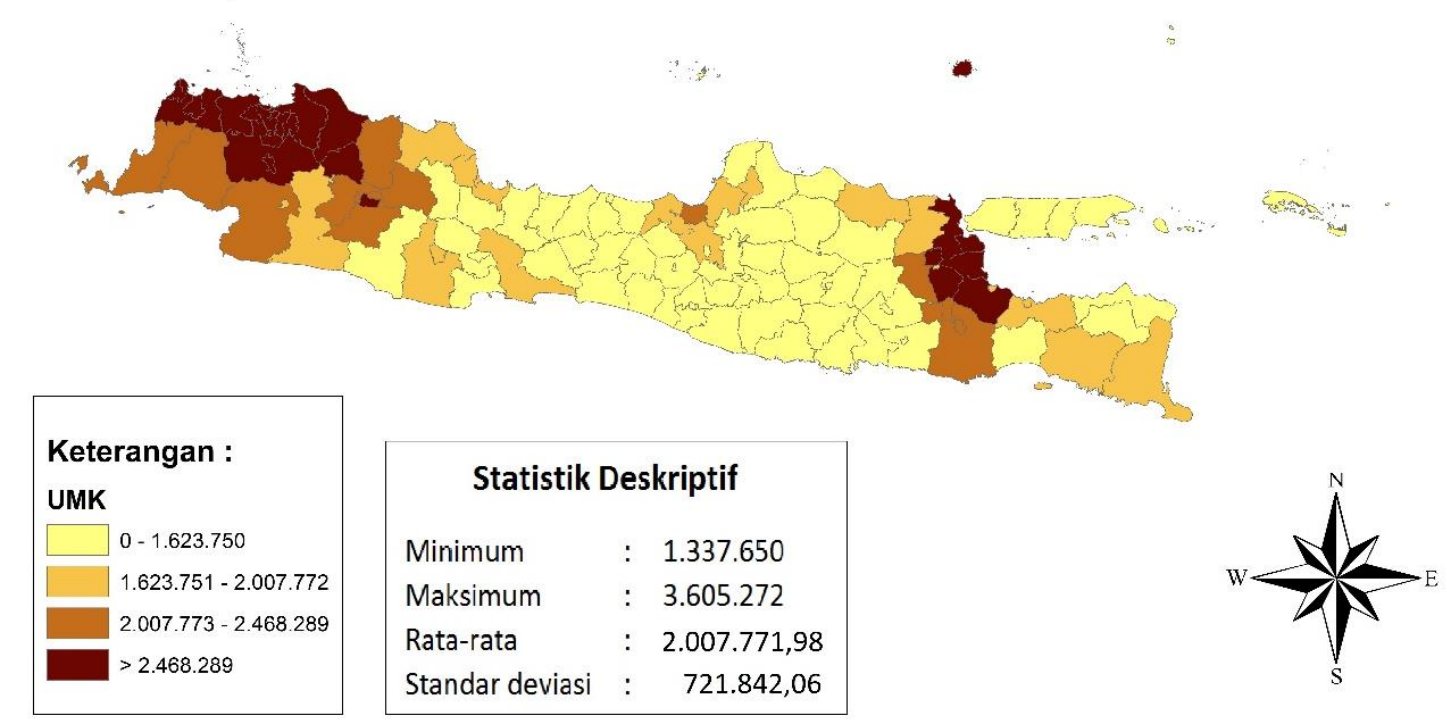

Keterangan: Peta tidak berskala

Gambar 3: Pola persebaran UMK menurut kabupaten/kota di Pulau Jawa tahun 2017.

Upah minimum kabupaten/kota (UMK) merupakan upah bulanan terendah yang terdiri atas upah pokok termasuk tunjangan tetap yang ditetapkan oleh gubernur. Upah minimum dibentuk sebagai salah satu upaya untuk melindungi pekerja dari upah yang sangat rendah. Wilayah dengan UMK tertinggi yaitu Kabupaten Karawang sebesar Rp3.605.272,00 dan wilayah dengan UMK terendah yaitu Kabupaten Gunung Kidul sebesar Rp1.337.650,00. Rata-rata UMK di Pulau Jawa sebesar Rp2.007.772,00 dengan tingkat keragaman UMK antar wilayah di Pulau Jawa cukup besar yaitu sekitar Rp721.842,06. Berdasarkan Gambar 3 terlihat bahwa kebanyakan kabupaten/kota di wilayah barat Pulau Jawa memiliki UMK yang cukup tinggi. Hal tersebut dikarenakan wilayah yang memiliki UMK tinggi merupakan daerah industri dan juga wilayah yang banyak berdiri perusahaan. Sementara, wilayah-wilayah bagian tengah dan timur Pulau Jawa memiliki kecendrungan menetapkan UMK dibawah rata-rata Pulau Jawa. 


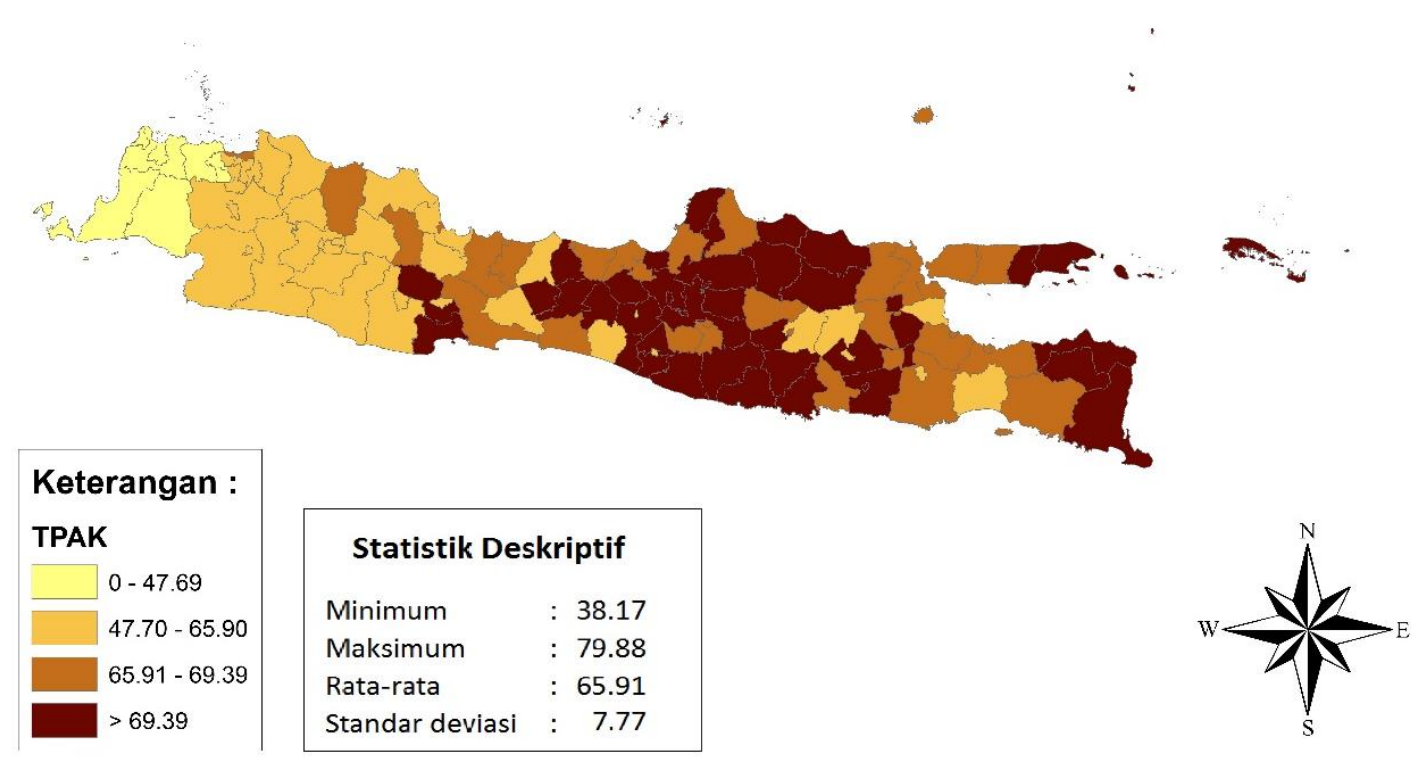

Keterangan: Peta tidak berskala

Gambar 4: Pola persebaran TPAK menurut kabupaten/Kota di Pulau Jawa tahun 2017.

Angka TPAK mengindikasikan besarnya persentase penduduk usia kerja yang aktif secara ekonomi di suatu wilayah. Semakin tinggi nilai TPAK menunjukkan bahwa semakin tinggi pula pasokan tenaga kerja yang tersedia untuk memproduksi barang atau jasa. Angka rata-rata TPAK kabupaten/kota di Pulau Jawa sebesar 65,91 yang berarti bahwa dari 100 penduduk usia kerja yang tinggal di Pulau Jawa terdapat sekitar 66 orang yang berpartisipasi aktif di pasar kerja. Wilayah dengan nilai TPAK tertinggi yaitu Kabupaten Pangandaran sebesar 79,88 persen dan wilayah dengan TPAK terendah yaitu Kabupaten Pandeglang sebesar 38,17 persen. Secara umum, keragaman TPAK antar wilayah di Pulau Jawa yaitu sebesar 7,77 persen. Berdasarkan Gambar 4 dapat dilihat bahwa TPAK kabupaten/kota di bagian tengah dan timur Pulau Jawa cenderung memiliki TPAK diatas rata-rata Pulau Jawa. Hal tersebut terjadi karena banyaknya lulusan sekolah menengah yang tidak melanjutkan ke jenjang perguruan tinggi dan memilih untuk terjun ke dunia kerja. Sementara, TPAK di kabupaten/kota di bagian barat Pulau Jawa cenderung berada dibawah rata-rata Pulau Jawa. Hal tersebut dikarenakan masih tingginya kesadaran penduduk untuk melanjutkan pendidikan ke jenjang yang lebih tinggi pada wilayah tersebut. 


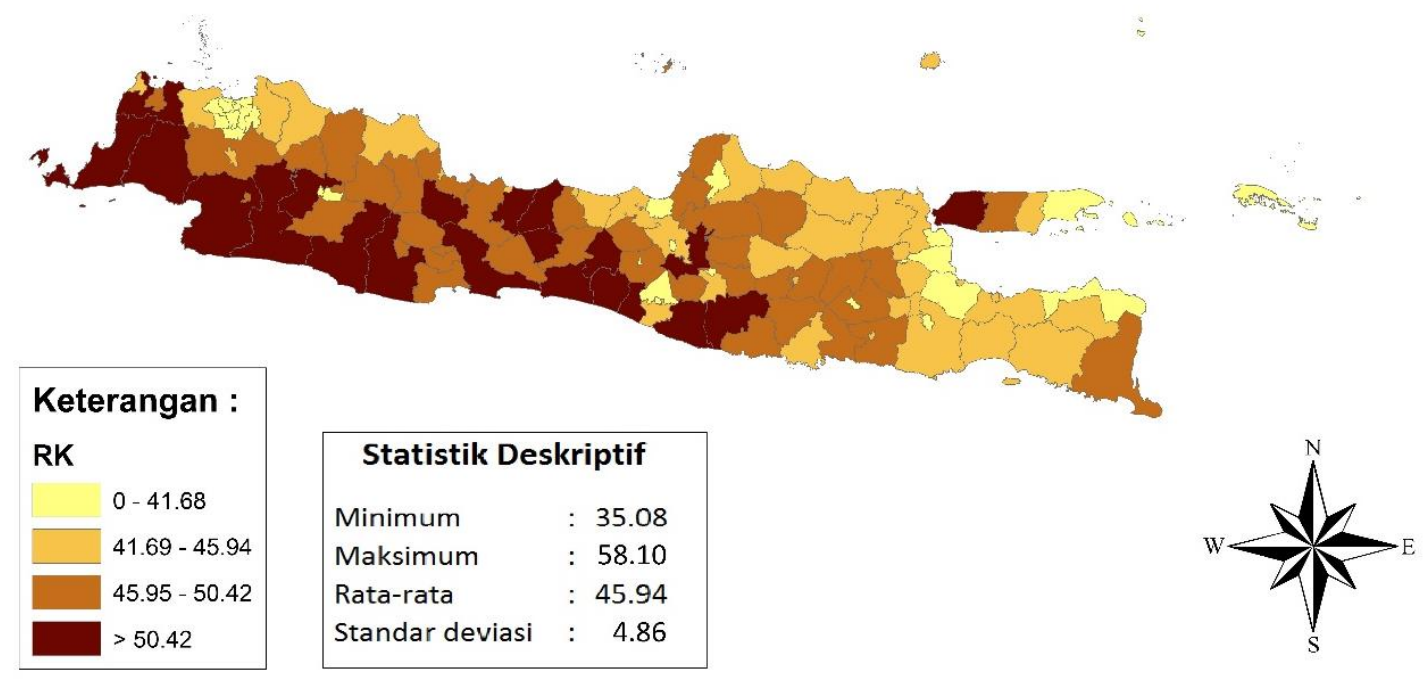

Keterangan: Peta tidak berskala

Gambar 5: Pola persebaran Rasio Ketergantungan menurut kabupaten/kota di Pulau Jawa tahun 2017.

Rasio ketergantungan merupakan suatu indikator yang secara kasar dapat menunjukkan keadaan ekonomi suatu negara, apakah tergolong maju atau negara yang sedang berkembang. Wilayah dengan angka rasio ketergantungan tertinggi yaitu Kabupaten Garut sebesar 58,10 persen dan wilayah dengan angka rasio ketergantungan terendah yaitu Kota Yogyakarta sebesar 35,08 persen. Rata-rata rasio ketergantungan di Pulau Jawa sebesar 45,94 dengan tingkat keragaman sebesar 4,86 persen. Berdasarkan Gambar 5 dapat dilihat bahwa kabupaten/kota di Provinsi Banten, Jawa Barat dan Jawa Tengah memiliki angka rasio ketergantungan diatas rata-rata Pulau Jawa. Kota-kota yang terdapat pada Provinsi DKI Jakarta memiliki angka rasio ketergantungan dibawah rata-rata Pulau Jawa yang menunjukkan bahwa beban penduduk bukan angkatan kerja di kota-kota tersebut tergolong rendah.

\subsection{Model GWR}

Tahap awal yang dilakukan dalam penelitian ini yaitu pembentukan model RLB dan pengecekan asumsi klasik dari metode estimasi OLS, yaitu asumsi normalitas, homoskedastisitas, nonautokorelasi dan nonmultikolinieritas. Pengujian normalitas residual menggunakan uji Jarque Berra diperoleh nilai statistik sebesar 1,58 , nilai ini lebih kecil dari titik kritis $\chi_{0,05 ; 2}^{2}=5,99$ sehingga disimpulkan bahwa residual data berdistribusi normal. Pada pengujian nonmultikolinieritas disimpulkan bahwa tidak terjadi multikolinieritas karena nilai VIF setiap variabel kurang dari 10 . Selain itu, pada pengujian homoskedastisitas menggunakan uji Breusch-Pagan menghasilkan nilai statistik sebesar 11,36 dan nilai ini lebih besar dari titik kritis $\chi_{0,05 ; 4}^{2}=9,49$ sehingga disimpulkan bahwa asumsi homoskedastisitas tidak terpenuhi, atau terdapat pengaruh heterogenitas dalam model. Pada pengujian nonautokorelasi menggunakan nilai Moran's I sebesar 0,7615 , lebih besar dari 0 dan mendekati 1 sehingga dapat disimpulkan bahwa terdapat autokorelasi spasial, hal ini berarti pola data membentuk kelompok dengan karakteristik yang sama. 
Dalam mengatasi masalah heterogenitas spasial dan autokorelasi spasial digunakan pemodelan dengan menggunakan metode GWR. Hal pertama yang dilakukan dalam pemodelan GWR adalah menentukan bandwidth. Amatan dalam penelitian ini tidak tersebar merata sehingga bandwidth yang digunakan adalah adaptive bandwidth. Dengan metode ini didapatkan bandwidth optimum sebesar 74 yang berarti terdapat 74 tetangga yang signifikan memiliki hubungan spasial dengan suatu wilayah. Selain itu, dipilih penimbang adaptive bi-square karena penimbang tersebut menghasilkan nilai AIC dan CV yang lebih kecil dibandingkan penimbang adaptive Gaussian.

Estimasi pada model GWR secara lokal akan menghasilkan koefisien regresi yang bervariasi pada setiap wilayah analisis. Sifat lokal dari model GWR dapat ditunjukkan dari hasil nilai estimasi parameternya yang berbeda-beda untuk setiap lokasi pengamatan karena setiap wilayah memiliki karakteristik yang berbeda. Ringkasan nilai estimasi parameter pada wilayah kabupaten/kota di Pulau Jawa dapat dilihat pada Tabel 1.

Tabel 1: Estimasi parameter model GWR.

\begin{tabular}{lrrr}
\hline \multicolumn{1}{c}{ Variabel } & Minimum & Median & Maksimum \\
\hline Konstanta & $-19,727$ & $-12,630$ & 22,171 \\
IPM & $-0,293$ & $-0,074$ & 0,078 \\
UMK & 1,290 & 2,277 & 3,779 \\
Rasio Ketergantungan & $-0,210$ & $-0,056$ & 0,031 \\
TPAK & $-0,322$ & $-0,125$ & $-0,032$ \\
\hline
\end{tabular}

Model GWR memungkinkan suatu variabel penjelas memiliki arah hubungan yang berbeda dengan variabel responnya di lokasi yang berbeda, sehingga suatu variabel bisa saja memiliki pengaruh positif di suatu lokasi namun memiliki hubungan negatif di lokasi lainnya (Fotheringham et al., 2003). Berdasarkan Tabel 1 dapat dilihat bahwa variabel IPM dan rasio ketergantungan memiliki hubungan positif dan negatif terhadap TPT di wilayah Pulau Jawa sedangkan variabel UMK memiliki hubungan positif dan variabel TPAK memiliki hubungan negatif.

Pada model GWR dilakukan uji variasi parameter untuk mendeteksi data yang mengandung heterogenitas spasial. Suatu variabel dikatakan memiliki heterogenitas spasial apabila difference of criterion bernilai negatif. Sebaliknya, jika nilainya positif maka menunjukkan bahwa variabel penjelas tersebut bersifat global.

\begin{tabular}{|c|c|}
\hline Variabel & Diff of Criterion \\
\hline Konstanta & $-746,54$ \\
\hline IPM & $-68,75$ \\
\hline TPAK & $-92,97$ \\
\hline UMK & $-309,64$ \\
\hline Rasio Ketergantungan & $-321,83$ \\
\hline
\end{tabular}


Tabel 2 menunjukkan nilai difference of criterion dari masing-masing variabel penjelas yang diduga memengaruhi TPT. Baik IPM, UMK, rasio ketergantungan maupun TPAK memiliki nilai difference of criterion yang negatif yang berarti seluruh variabel penjelas bersifat lokal pada masing-masing kabupaten/kota di Pulau Jawa.

Selanjutnya, dilakukan pengujian parsial pada parameter regresi secara lokal. Pengujian ini dilakukan dengan tujuan untuk mengetahui variabel penjelas apa saja yang berpengaruh signifikan terhadap TPT di suatu kabupaten/kota di Pulau Jawa. Hasil pengujian parsial signifikansi parameter lokal disajikan dalam sebuah peta tematik. Gambar 6 menunjukkan bahwa terdapat kesamaan variabel penjelas yang signifikan memengaruhi TPT pada wilayah-wilayah yang berdekatan. Kabupaten/kota di Pulau Jawa mengelompok menjadi 7 kelompok berdasarkan variabel penjelas yang signifikan. Di bagian timur Pulau Jawa variabel penjelas yang signifikan adalah UMK dan TPAK, sementara di bagian barat semua variabel kecuali TPAK signifikan. Terdapat 23 kabupaten/kota yang semua variabel penjelasnya signifikan, kabupaten/kota ini mengelompok di bagian timur Jawa Barat dan bagian barat Jawa Tengah.

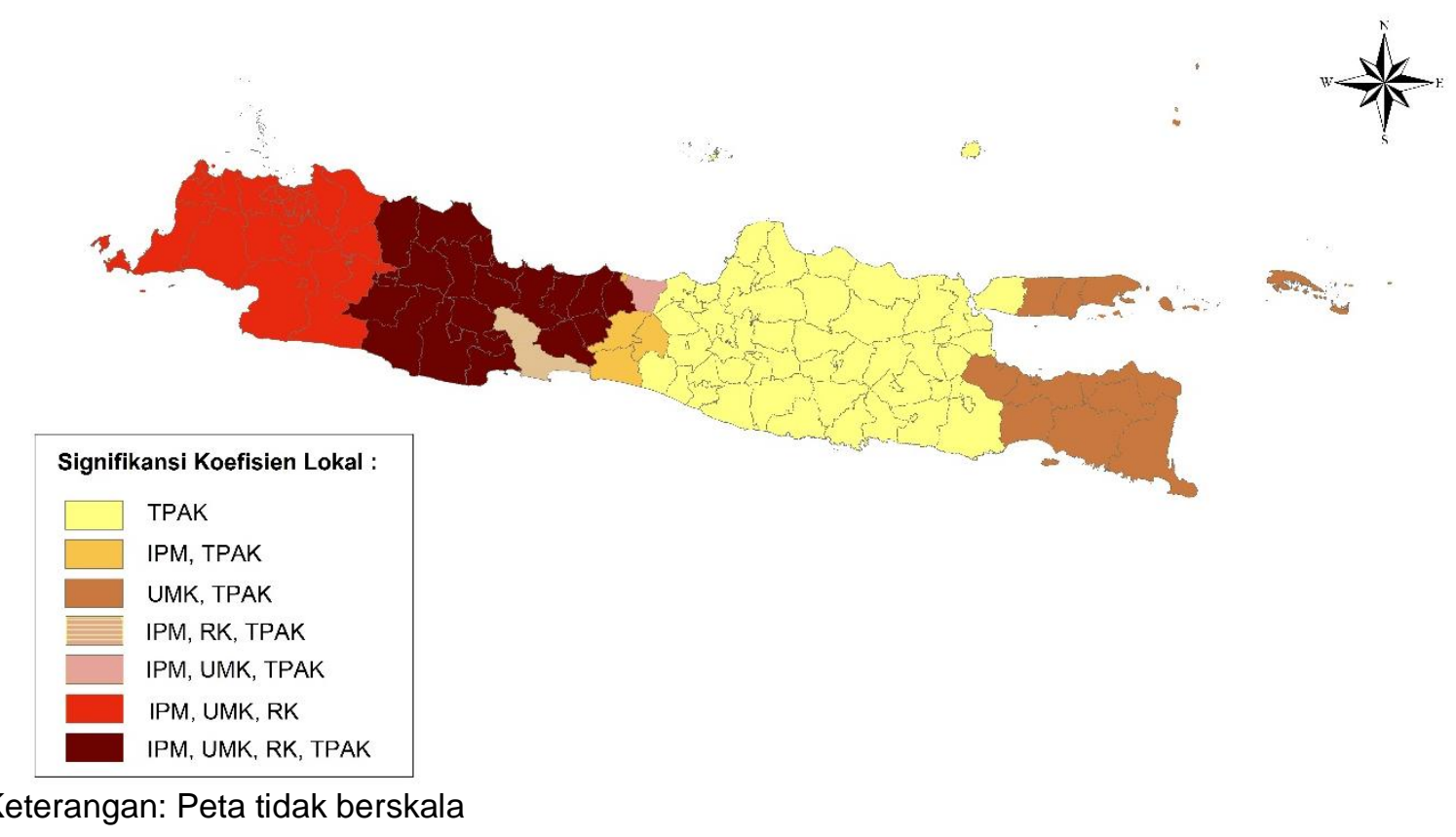

Gambar 6: Peta pengelompokan kabupaten/kota di Pulau Jawa berdasarkan variabel penjelas yang signifikan.

Evaluasi model GWR yang terbentuk perlu dilakukan untuk meninjau apakah model GWR ini dapat mengatasi masalah heterogenitas spasial maupun autokorelasi spasial. Untuk melihat apakah GWR dapat mengatasi masalah autokorelasi spasial dilihat melalui nilai Moran's I dan juga Moran's Scatterplot pada residual model GWR. Nilai Moran's I yang dihasilkan mendekati nol yang berarti residual model GWR tidak lagi mengandung autokorelasi spasial. Selain itu disajikan Gambar 7 untuk menjelaskan pola sebaran residual yang terjadi. Berdasarkan gambar tersebut dapat dilihat bahwa residual cenderung tersebar secara acak di seluruh kabupaten/kota di pulau Jawa dan tidak memiliki pola spasial tertentu. Dengan demikian dapat dikatakan bahwa model GWR dapat mengatasi masalah heterogenitas spasial. 


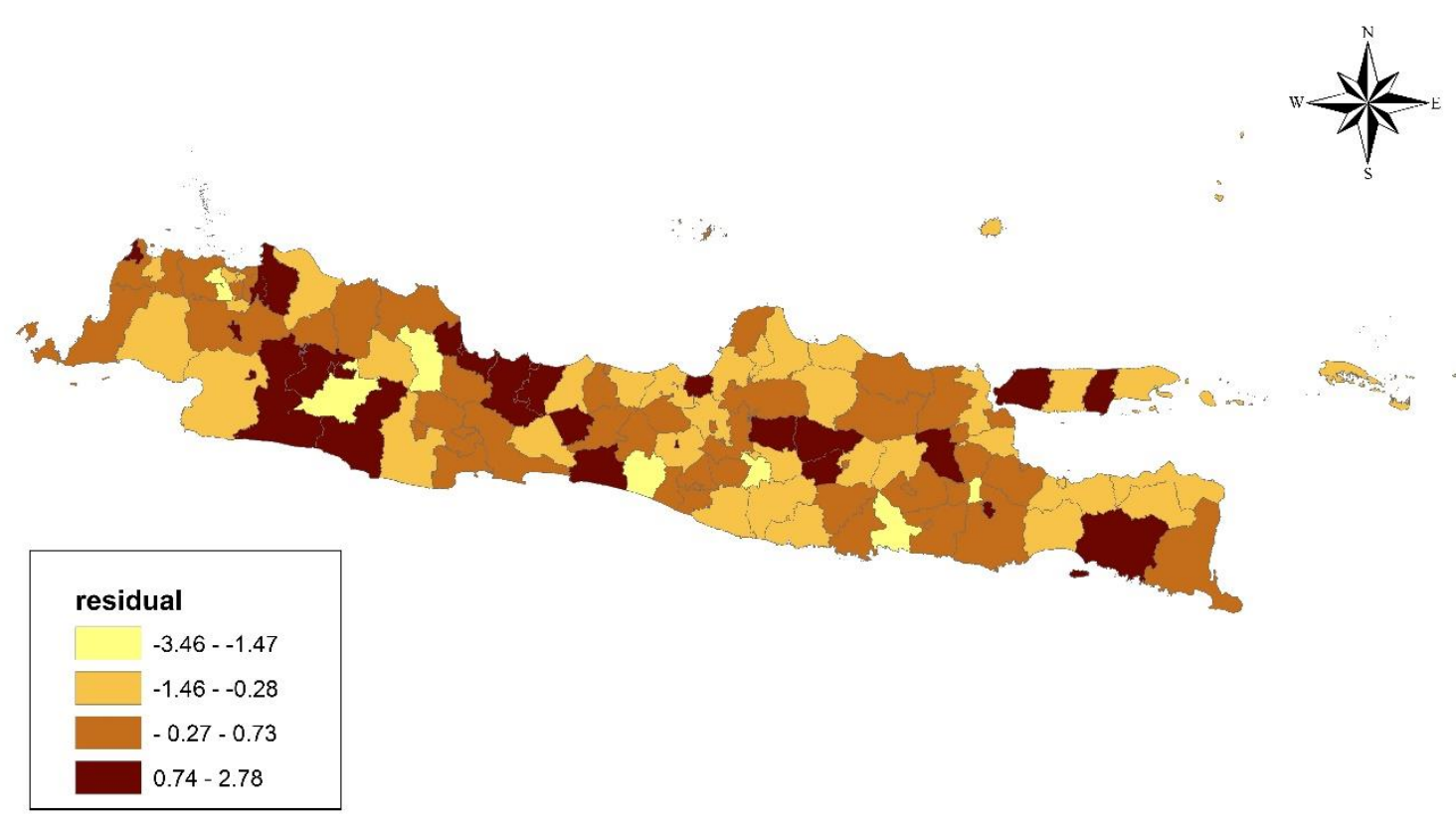

Keterangan: Peta tidak berskala

Gambar 7: Sebaran residual dari pemodelan GWR di pulau Jawa tahun 2017.

Model GWR menghasilkan 119 persamaan regresi yang mewakili hubungan antara variabel penjelas dengan TPT pada setiap kabupaten/kota di Pulau Jawa. Sebagai contoh ditampilkan persamaan regresi untuk Kabupaten Tasikmalaya, sebagai berikut:

$$
\begin{gathered}
\widehat{T P T}_{\text {Tasikmalaya }}=-3,90-0,23 I P M_{\text {Tasikmalaya }}+2,91 \ln (U M K)_{\text {Tasikmalaya }} \\
-0,16 R_{\text {Tasikmalaya }}-0,11 T P A K_{\text {Tasikmalaya }}
\end{gathered}
$$

Interpretasi dari persamaan regresi Tasikmalaya adalah:

- Koefisien pada variabel IPM sebesar -0,23 yang artinya setiap peningkatan 1 satuan IPM akan menurunkan TPT sebesar 0,23 persen. Hal tersebut sesuai dengan penelitian yang dilakukan oleh Burhanudin (2016) yang menyimpulkan bahwa terdapat hubungan negatif dan signifikan antara IPM dengan TPT yang menunjukkan bahwa apabila terjadi peningkatan pada komponen IPM yaitu kesehatan, pendidikan, dan kemampuan daya beli maka TPT akan semakin berkurang. Ketika terjadi peningkatan kualitas manusia maka hal tersebut berdampak pada pemikiran seseorang untuk menciptakan lapangan kerja, bukan sekadar mendapatkan pekerjaan, sehingga dapat mengurangi angka pengangguran.

- Koefisien pada variabel TPAK sebesar -0,11 yang berarti setiap peningkatan 1 persen TPAK akan menurunkan TPT sebesar 0,11 persen. Hal tersebut sesuai dengan penelitian llahi et al., (2014) yang menyimpulkan bahwa terdapat hubungan negatif dan signifikan antara TPAK dan TPT. Hal tersebut menunjukkan bahwa partisipasi kerja berbanding lurus dengan penurunan angka TPT. 
- Koefisien pada variabel UMK sebesar 2,91 yang berarti setiap peningkatan pertumbuhan UMK sebesar 1 persen akan meningkatkan TPT sebesar 2,91 persen. Hal tersebut sesuai dengan penelitian yang dilakukan oleh Hajji \& Nugroho (2013) yang menyimpulkan bahwa terdapat hubungan positif dan signifikan antara upah minimum dengan TPT. Hal ini disebabkan karena upah minimum yang ditetapkan selalu mengalami kenaikan dan berada diatas keseimbangan pasar yang menyebabkan membengkaknya biaya produksi perusahaan. Sehingga untuk mencegah inefesiensi tenaga kerja, maka perusahaan akan mengurangi jumlah tenaga kerja yang berakibat pengangguran akan bertambah.

- Koefisien pada variabel rasio ketergantungan sebesar -0,16 yang berarti setiap peningkatan 1 satuan rasio ketergantungan akan menurunkan TPT sebesar 0,16 persen. Hal tersebut tidak sesuai dengan penelitian Putro \& Setiawan (2013) yang menyimpulkan bahwa ketika rasio ketergantungan naik maka akan menyebabkan kenaikan TPT. Namun, sesuai dengan penelitian yang dilakukan oleh Wijaya (2018) dengan metode regresi nonparametric spline truncated menyimpulkan bahwa rasio ketergantungan memiliki hubungan negatif sekaligus positif. Hal tersebut menunjukkan bahwa pada kondisi tertentu, hubungan antara rasio ketergantungan bisa positif maupun negatif terhadap TPT.

\section{Simpulan}

Berdasarkan hasil dan pembahasan yang telah dipaparkan sebelumnya, maka kesimpulan yang dapat diambil dari penelitian ini adalah:

1. Pola persebaran TPT di Pulau Jawa tidak merata, TPT mayoritas masih tinggi di Pulau Jawa bagian barat.

2. Pengaruh IPM, UMK, rasio ketergantungan, TPAK terhadap TPT berbeda-beda, dapat berpengaruh positif maupun negatif.

\section{Daftar Pustaka}

Burhanudin, M. (2016). Pengaruh produk domestik regional bruto (PDRB), upah minimum kabupaten/kota (UMK), dan indeks pembangunan manusia (IPM) terhadap tingkat pengangguran di Provinsi Banten periode 2008-2013 [skripsi]. Jakarta: UIN Syarif Hidayatullah.

Fotheringham, A.S., Brunsdon, C., and Charlton, M. (2003). Geographically weighted regression: the analysis of spatially varying relationships. Chichester, UK: John Wiley \& Sons.

Hajji, M.S., and Nugroho, S. (2013). Analisis PDRB, inflasi, upah minimum provinsi, dan angka melek huruf terhadap tingkat pengangguran terbuka di Provinsi Jawa Tengah tahun 1990-2011. Diponegoro Journal of Economics, 2(3): 36-45.

Ilahi, R., Syamsuddin, M., and Suparman, Y. (2014). Model spasial durbin dengan efek tetap untuk tingkat pengangguran terbuka di Provinsi Kepulauan Bangka Belitung, in: Prosiding Seminar Nasional Statistika, Departemen Statistika FMIPA Universitas Padjadjaran. pp. 424-436. 
Mulyani, F. (2017). Determinan kemiskinan di kawasan timur indonesia (KTI) tahun 2015 menggunakan metode geographically weighted regression (GWR) [skripsi]. STIS, Jakarta.

Nakaya, T. (2012). GWR4 user manual. WWW document.

Putro, A.S., and Setiawan, A.H. (2013). Analisis pengaruh produk domestik regional bruto, tingkat upah minimum kota, tingkat inflasi dan beban/tanggungan penduduk terhadap pengangguran terbuka di Kota Magelang periode tahun 1990-2010. Diponegoro Journal of Economics, 2(3):12-25.

Sukirno, S. (2010). Teori pengantar makroekonomi edisi ketiga. Jakarta: PT. Raja Grafindo Pesada.

Wijaya, A.F.H. (2018). Analisis faktor-faktor yang mempengaruhi tingkat pengangguran terbuka (TPT) di Provinsi Aceh dengan regresi nonparametrik spline truncated [skripsi]. Surabaya: Institut Teknologi Sepuluh Nopember. 